\title{
Protective Effect of Capparis spinosa Hydroalcoholic Extract on the Integrity of Rat Pancreatic Islets
}

\author{
Mohsen Azad 1(D), Perham Mohammadi 2 (D), Shahab Bohlooli 1(D), Sara Mostafalou 1*(D)
}

1. Dept. of Pharmacology and Toxicology, School of Pharmacy, Ardabil University of Medical Sciences, Ardabil, Iran

2. Dept. of Physiology and Pharmacology, School of Medicine, Ardabil University of Medical sciences, Ardabil, Iran

\begin{tabular}{|c|c|}
\hline Article Info & ABSTRACT \\
\hline dof $10.30699 /$ jambs.28.129.204 & \multirow{3}{*}{$\begin{array}{l}\text { Background \& Objective: Capparis spinosa L. belongs to the Capparaceae } \\
\text { family for which biological roles such as antioxidant, anti-inflammatory, and } \\
\text { antidiabetic effects have been reported. Some active chemical groups including } \\
\text { flavonoids, phenols, alkaloids, tannins, and minerals have been detected in this } \\
\text { plant. This study aimed to extract the } C \text {. spinosa alcoholic extract from different } \\
\text { parts of the plant, measure the content of phenols and flavonoids, and evaluate the } \\
\text { effects of bud extracts on the viability and oxidative state of the islets of Langerhans } \\
\text { isolated from rat pancreas. }\end{array}$} \\
\hline $\begin{array}{l}\text { Received: 2020/04/18; } \\
\text { Accepted: 2020/07/15; } \\
\text { Published Online: } 31 \text { July 2020; }\end{array}$ & \\
\hline $\begin{array}{l}\text { Use your device to scan and read the } \\
\text { article online }\end{array}$ & \\
\hline \multirow[t]{2}{*}{ 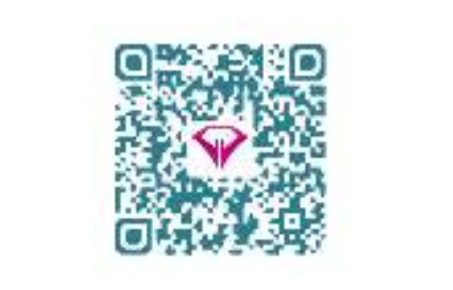 } & $\begin{array}{l}\text { Materials \& Methods: In this experimental setup, the hydroalcoholic extracts of } \\
\text { different parts of the plant were obtained based on the maceration method. Folin- } \\
\text { Ciocalteu and rutin were used as the standard reagents to measure phenols and } \\
\text { flavonoids. The islets of Langerhans were isolated from the pancreas of male rats } \\
(\mathrm{n}=16 \text { ) and incubated for } 24 \text { hours. Then, the islets were exposed to the plant extract } \\
\text { for } 24 \text { hours after which cellular viability and reactive oxygen species were measured. }\end{array}$ \\
\hline & Results: The C. spinosa bud alcoholic extrac \\
\hline \multirow{3}{*}{$\begin{array}{l}\text { Corresponding Information: } \\
\text { Sara Mostafalou, } \\
\text { Dept. of Pharmacology and } \\
\text { Toxicology, School of Pharmacy, } \\
\text { Ardabil University of Medical } \\
\text { Sciences, Ardabil, Iran }\end{array}$} & $\begin{array}{l}\text { islet cells. This effect was dose-dependent, and the greatest effects were observed } \\
\text { at } 10^{3} \text { and } 10^{4} \mu \text { gmL- } 1 \text {. At the mentioned concentrations, ROS production was reduced } \\
\text { by } 37 \% \text { and } 72 \% \text { respectively comparing to the control. }\end{array}$ \\
\hline & \\
\hline & $\begin{array}{l}\text { Conclusion: The results indicated that } C \text {. spinose may have protective effects on } \\
\text { the endocrine pancreas by increasing viability and decreasing ROS in the islets, and } \\
\text { can thus be considered as a promising agent for prophylaxis and therapy in diabetes } \\
\text { management. }\end{array}$ \\
\hline $\begin{array}{l}\text { E-Mail: } \\
\text { s.mostafalou@pharmacy.arums.ac.ir }\end{array}$ & Keywords: Capparis spinosa L, Diabetes, Pancreas, Insulin, Oxidative stress \\
\hline (ख) & $\begin{array}{l}\text { sarticle distributed under the terms of the Creative } \mathrm{Cr} \\
\text { icommercial usages with proper citation. }\end{array}$ \\
\hline
\end{tabular}

\section{Introduction}

Diabetes mellitus (DM) is known as the century's metabolic disease with different etiologies, affecting many organs (1) and causing several complications such as renal, ocular, and cardiovascular problems (2). The number of people suffering from DM is increasing; it is estimated that there are $\sim 451$ million people with diabetes worldwide, and this value is expected to reach 693 million by 2045 (3).

The exact pathophysiology of diabetes is related to the uncontrolled blood glucose concentration that can be due to a defect in the secretion or peripheral responsiveness of insulin. Disturbed cellular homeostasis in the organs responsible for glucose metabolism can deteriorate the pathophysiology of diabetes and related complications. The normal homeostasis of the living cells is determined by the ADP/ATP ratio and reactive oxygen species (ROS) level whose overproduction can saturate the antioxidant defense of the cell and lead to oxidative stress. Oxidative stress occurs when radicals and ROS increase during metabolism and overwhelm antioxidant defensive molecules. ROS can damage cellular nucleic acids, proteins, and lipids, leading to cellular necrosis that has been known to be involved in age-related diseases such as neurodegeneration and diabetes $(4,5)$. In this way, preventing the excess production of ROS in the cells by supporting antioxidant reservoirs is under comprehensive studies as a promising strategy for the treatment of the mentioned diseases. It has been shown that reducing ROS formation in the pancreatic cells by using antioxidants increases insulin gene expression, insulin release, and viability of Langerhans islets (6).

Currently, there exist some synthetic antioxidants in use which may have several adverse effects (7). Some plants contain molecules that can neutralize oxidative elements overproduced in the cells, and have been proposed as the natural sources of antioxidants (5). 
Since antiquity, plants have been used to cure several diseases, and many medicinal plants show antidiabetic activities (8). Capparis spinosa L., known as capper, belongs to the Capparaceae family; there are some reports on the antimicrobial, antioxidant, antiinflammatory, antimutagenic, and blood glucoselowering effects of this family of plants (9). Phenols, flavonoids, alkaloids, tannins, and minerals are the main active chemical groups detected in capper (10). Among these, phenolic compounds have been demonstrated to scavenge free radicals in the cells. This is why the plants rich in phenolic compounds are considered as therapeutic candidates for human health problems due to their antioxidant and antiinflammatory properties (11).

The present study aimed to measure the phenol and flavonoid content of the hydroalcoholic and methanolic extracts of the bud, roots, and leaf of $C$. spinose obtained from the Moghan area in Ardabil Province, Iran, and screen the effect of bud ethanolic extract on the viability and oxidative markers of the rat islets of Langerhans.

\section{Materials and Methods}

\section{Research Approval}

This work is based on a thesis for a degree in pharmacy at the School of Pharmacy, Ardabil University of Medical Sciences, Ardabil, Iran. All the processes were approved by the Ethics Committee of Ardabil University of Medical Sciences (approval ID: IR.ARUMS.REC.1397.174).

\section{Chemicals}

Aluminum trichloride, bovine serum albumin (BSA), Dichloro-dihydro-fluorescein diacetate (DCFH-DA), Folin-Ciocalteu, gallicacid, HEPES sodium salt, 3(4,5-dimethylthiazol- 2-yr)-2,5-diphenyltetrazolium bromide (MTT), rutin, and the RPMI 1640 medium were purchased from Sigma-Aldrich Co.

\section{Plant Materials and Preparation}

C. spinosa L. leaf, bud, and roots were used in this study. They were collected from the Moghan district of Ardabil, Iran, in June 2018. After cleaning the collected parts of the plant, they were dried under the shade at room temperature and then powdered. The maceration method was adopted to obtain alcoholic extracts of different parts of the plant. Briefly, $25 \mathrm{~g}$ of the plant powder from each part was treated with $250 \mathrm{~mL}$ of methyl alcohol (99\%) in a tightly closed container for two days. The container was shaken one or two times a day. Then, the mixture was filtered and the solvent was removed by using a rotary evaporator. Hydroalcoholic extracts were also prepared by treating $25 \mathrm{~g}$ of the plant powder from each part with $250 \mathrm{~mL}$ of ethanol $(80 \%)$ as the solvent, and the same procedures were followed. The residues were dissolved and used for the following experiments.

\section{Phenolic Content Determination}

The content of total phenols in the extracts was measured with the reagent Folin- Ciocalteu. In this experiment, $100 \mu \mathrm{L}$ of the plant extracts and $500 \mu \mathrm{L}$ of the Folin-Ciocalteu reagent were added to $1.5 \mathrm{~mL}$ of sodiumcarbonate $(20 \%)$. After shaking the mixture, it was diluted with distilled water up to $10 \mathrm{~mL}$ and left for $2 \mathrm{~h}$. Subsequently, the absorbance of the mixture was determined at $765 \mathrm{~nm}$. A standard curve was plotted from the different concentrations of gallic acid so that the content of total phenols would be expressed as $\mathrm{mg} / \mathrm{g}$ gallic acid equivalents (GAE) (12).

\section{Flavonoid Content Determination}

We followed a method from the State Pharmacopeia of USSR for the measurement of flavonoid content in the extracts by using rutin as the reference compound. Rutin, which was available in our lab, is a common flavonoid commonly used as a standard in the determination of total flavonoid content (13). Briefly, one drop of acetic acid was added to a mixture containing $1 \mathrm{~mL}$ of the extract in methanol $(10 \mathrm{mg} / \mathrm{mL})$ and $1 \mathrm{~mL}$ of aluminum trichloride in ethanol (20 $\mathrm{mg} / \mathrm{mL}$ ), and then made up to $25 \mathrm{~mL}$ by ethanol. After 40 mins, the absorbance of the mixture was determined at $415 \mathrm{~nm}$. To prepare the blank samples, one drop of acetic acid was added to $1 \mathrm{~mL}$ of the extract and then ethanol was added to $25 \mathrm{~mL}$. A standard solution containing rutin $(0.5 \mathrm{mg} / \mathrm{mL})$ in ethanol was used to plot the standard curve. The rutin equivalent (RE) was used to quantify the flavonoid content in the extracts according to the following formula; $\mathrm{X}=\left(\mathrm{A} * \mathrm{~m}_{0}\right)\left(\mathrm{A}_{0}\right.$ $* \mathrm{~m})$ where $\mathrm{X}$ means the content of flavonoids $(\mathrm{mg} / \mathrm{mg}$ extract inRE), $\mathrm{A}$ and $\mathrm{A}_{0}$ denote the absorbance of extract solution and standard solution, respectively, and $\mathrm{m}$ and $\mathrm{m}_{0}$ express the weight of the plant extract (mg) and rutin (mg) in the solution, respectively (14).

\section{Animals}

Adult male Wistar rats weighting 200-250 g were used $(n=16)$; all the animal experimental procedures were approved by the Ethics Committee of Ardabil University of Medical Sciences (IR.ARUMS.REC.1397.174).

\section{Isolation of Pancreatic Islets of Langerhans}

Before starting the experimental procedure, a suitable period of time was given to the animals to spend in the lab environment. A solution containing ketamine and xylazine at a ratio of 10:1 (the administered dose of $100 \mathrm{mg} / \mathrm{kg}$ ketamine and 10 $\mathrm{mg} / \mathrm{kg}$ xylazine) was intraperitoneally injected and, after anesthetization, the animals were subjected to laparotomy. The pancreatic duct was cannulated for perfusion with a cold and fresh Krebs buffer which made the pancreas swollen and easy to isolate from the other parts. Then, the pancreas was chopped and cut off into small pieces by using a small scissor in the cold Krebs buffer. Collagenase was added to the homogenate to breakdown the tissue around the islets. After the separation of fat tissues, the homogenate was washed with Krebs buffer in triplicate. Next, BSA was added and washed twice in order to stop digestion. 
Finally, islets of Langerhans were picked up by using a sampler under the stereomicroscope, grouped based on similarity in size, and cultured in RPMI 1640. The cultured islets were incubated for $24 \mathrm{~h}$ at $37^{\circ} \mathrm{C}$ to overcome stressful conditions and restore their viability in the nourished and refreshed medium (15).

\section{Pancreatic Islets' Treatment with the Plant Extract}

After $24 \mathrm{~h}$ of pretreatment time, the islets were incubated with logarithmic concentrations of hydroalcoholic extracts of the bud, including $10,10^{2}, 10^{3}, 10^{4} \mu \mathrm{g} / \mathrm{mL}$ in the RPMI medium for $24 \mathrm{~h}$.

\section{Viability Assay in the Pancreatic Islets}

The MTT assay is based on the reducing capacity of yellow tetrazole into purple formazan by viable cells having the normal mitochondrial respiration. After 24 $\mathrm{h}$ of treatment of pancreatic islets with hydroalcoholic extracts, we removed the medium and washed the islets of Langerhans with Krebs buffer twice. Then, $50 \mu \mathrm{L}$ of the MTT solution $(0.5 \mathrm{mg} / \mathrm{mL})$ was added to each vial of the islets and incubated for $4 \mathrm{~h}$ at $37^{\circ} \mathrm{C}$. The islets having viable cells converted the yellow tetrazole into purple formazan, which was dissolved in the solution by adding DMSO and shaking for $30 \mathrm{~min}$. Finally, a microplate reader was employed to read the absorbance of the samples at $570 \mathrm{~nm}(16)$.

\section{ROS Assay in the Pancreatic Islets}

The ROS level was measured using the DCFH-DA. ROS deacetylate and oxidize non-fluorescent DCFHDA into the fluorescent DCF inside the cells. The islets of Langerhans were sonicated in $75 \mu \mathrm{L}$ of the extraction buffer (containing $5 \mathrm{mM}$ HEPES, 20 $\mathrm{mMKCl}, 1 \mathrm{mM}$ EDTA, $0.25 \mathrm{mM}$ sucrose) and $10 \mu \mathrm{L}$ of the DTT solution $(50 \mathrm{mM})$, and then centrifuged at $5000 \mathrm{rpm}$ for $5 \mathrm{~min}$. In the next step, we extracted 25 $\mu \mathrm{L}$ of the supernatant and mixed it with $80 \mu \mathrm{L}$ of the assay buffer (containing $0.1 \mathrm{mM} \mathrm{FeCl}_{3}, 20 \mathrm{mM} \mathrm{MgCl} 2$, 20 mM NaH2PO4, 130 mMKCl, 20 mMTris-HCl, 0.1 $\mathrm{mM}$ NADPH, and $1.7 \mathrm{mM}$ ADP). Finally, $5 \mu \mathrm{L}$ of DCFH-DA was added to the mixture and incubated for

$1 \mathrm{~A}$

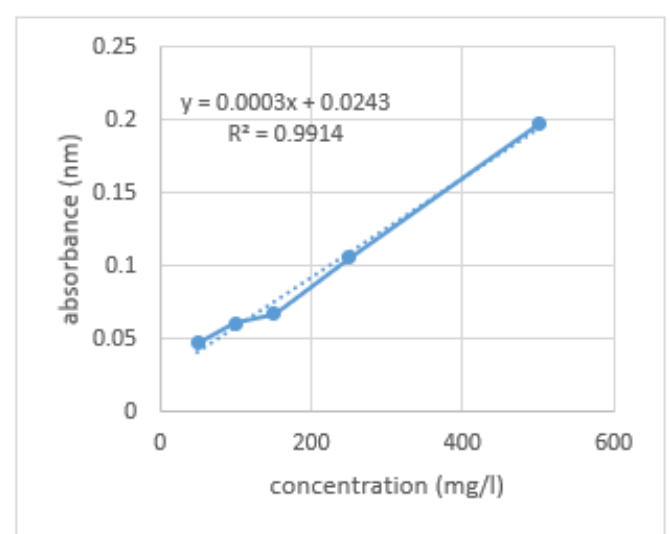

Figure 1. Calibration curve for gallic acid (A) and rutin (B).
$15 \mathrm{~min}$ at $37^{\circ} \mathrm{C}$. During this time, DCFH-DA could enter the cells and be hydrolyzed by intracellular esterase to produce free DCFH. Measurement of the rate of DCF production through the oxidation of DCFH is an indicator of the amount of ROS in the cells. In this way, the absorbance of the mixture was read at an excitation of 485/20 and an emission of 528/20 every $5 \mathrm{~min}$ for $1 \mathrm{~h}$ with a fluorometer (Biotec, Tecan US, Inc.) (17).

\section{Protein Assay in the Pancreatic Islets}

The amount of total protein was assessed by the Bradford method in which BSA was used as the standard. Briefly, we added $100 \mu \mathrm{L}$ of the Bradford reagent to $5 \mu \mathrm{L}$ of each sample supernatant and standard solutions. After $20 \mathrm{~min}$ of incubation, we read the absorbance of the solutions by the spectrophotometer at $595 \mathrm{~nm}$.

\section{Statistical Analysis}

The data were analyzed by SPSS and expressed as mean \pm SEMwith a replication number, $n=4$. The Pvalue of differences among the means were analyzed by one-way ANOVA followed by Tukey's test.

\section{Results}

In the first phase of the study, the phenol and flavonoid content of the methanolic and hydroalcoholic extracts of different parts of $C$. spinosa from the Moghan region were measured. In the second phase, the effects of the bud hydroalcoholic extract on the oxidative state and viability of rat pancreas were evaluated.

\section{Calibration Curve for Plant Reagent Determination}

We used gallic acid as the standard compound for the measurement of total phenolic content. The calibration curve of gallic acid was plotted with a regression of 0.9914 (Figure 1A). For determining flavonoid content, rutin was used as the standard compound, for which a calibration curve was drawn with a regression of 0.9848 (Figure 1B).

$$
1 \mathrm{~B}
$$

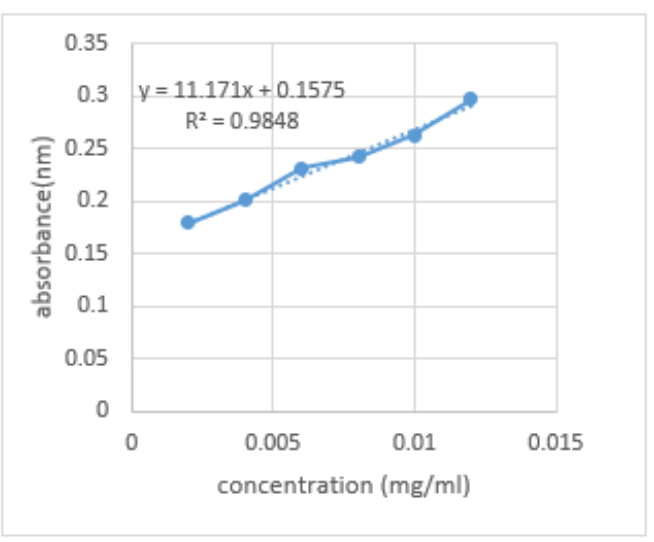




\section{Phenolic Content in Different Parts of the Plant}

As shown in Table 1, phenolic compounds had the highest content in the plant extract in comparison with others, and the leaf methanolic extract had the highest phenolic content (598.99 mg/g GAE). The root content of phenols was so low that it was ignored.

\section{Flavonoid Content in Different Parts of the Plant}

Flavonoids were less than phenols, and the amount of flavonoids in the leaf and bud had no significant differences (Table 1). The root content of flavonoids was also so low that could be ignored.

Table 1. Yield, total phenolic, flavonoid, and flavonol contents in the bud, leaf, and root methanolic and ethanolic extracts of C. spinose

\begin{tabular}{|c|c|c|c|c|c|}
\hline & & Yield (\%) & $\begin{array}{l}\text { Total phenols } \mathrm{mg} / \mathrm{g} \\
\text { plant extract } \\
\text { (in GAE) }\end{array}$ & $\begin{array}{c}\text { Total flavonoids mg/g plant } \\
\text { extract } \\
\text { (in RE) }\end{array}$ & $\begin{array}{l}\text { Total flavonols mg/g } \\
\text { plant extract (in RE) }\end{array}$ \\
\hline \multirow{2}{*}{ Bud } & Ethanolic & 27.2 & $318.99 \pm 17.63$ & $318.99 \pm 17.63$ & $40.21 \pm 0.3$ \\
\hline & Methanolic & 26.28 & $328.99 \pm 29.06$ & $328.99 \pm 29.06$ & $34.49 \pm 0.16$ \\
\hline \multirow{2}{*}{ Leaf } & Ethanolic & 18.8 & $534.55 \pm 18.36$ & $534.55 \pm 18.36$ & $32 \pm 2.23$ \\
\hline & Methanolic & 17.6 & $598.99 \pm 20.27$ & $598.99 \pm 20.27$ & $47.41 \pm 2,41$ \\
\hline \multirow{2}{*}{ Root } & Ethanolic & 19.8 & $16.77 \pm 13.87$ & $16.77 \pm 13.87$ & $2.1 \pm 0.1$ \\
\hline & Methanolic & 11.88 & $130.11 \pm 8.39$ & $130.11 \pm 8.39$ & $2.31 \pm 0.1$ \\
\hline
\end{tabular}

Effect of the Plant Bud Extract on the Viability of Pancreatic Islets

Based on Figure 2, the C. spinosa bud hydroalcoholic extract markedly increased the survival of the islet cells. This effect was positively related to the concentration of the plant extract, and the greatest effect was observed at the concentration of $\sim 10^{3}$ and $10^{4} \mu \mathrm{g} / \mathrm{mL}(P<0.001)$.

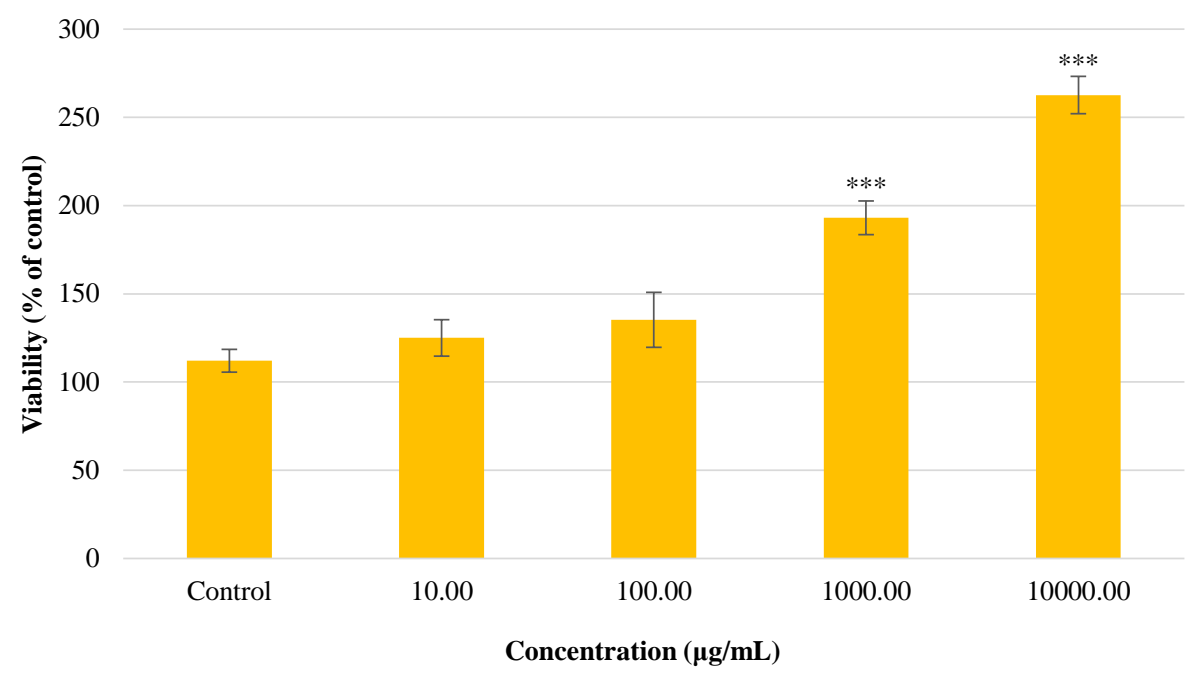

Figure 2. Effect of different concentration of $C$. Spinosa on the viability of islets of Langerhans isolated from the pancreas of rat after $24 \mathrm{~h}$ of exposure. Values are expressed as mean \pm SEM with a replication number, $n=4$. ***significantly different from the control at P-value $<\mathbf{0 . 0 0 1}$.

Effect of the Plant Bud Extract on ROS Level in the Pancreatic Islets

Volume 28, July \& August 2020
As seen in Figure 3, there were remarkable reductions in ROS production compared with the control when the plant extract was used at the concentrations of $10^{3} \mu \mathrm{g} / \mathrm{mL}(P<0.01)$ and $10^{4} \mu \mathrm{g} / \mathrm{mL}$ 
$(P<0.001)$. The rate of decrease in ROS production was estimated to be $37 \%$ and $72 \%$ of the control in the mentioned treated groups, in that order.

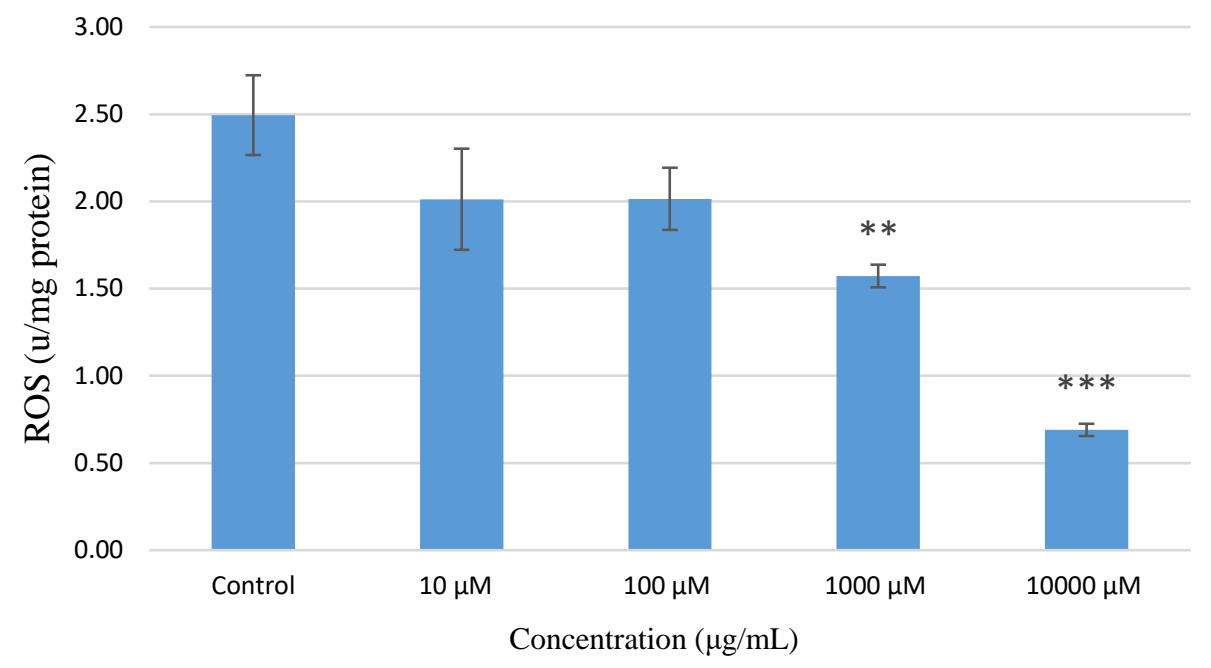

Figure 3. Effect of different concentration of $C$. Spinosa on the level of ROS in the islets of Langerhans isolated from the pancreas of rat after $24 \mathrm{~h}$ of exposure. Values are expressed as mean \pm SEM with a replication number, $n=4$. **significantly different from the control at P-value $<0.01$, ***significantly different from the control at $P$-value $<0.001$.

\section{Discussion}

Diabetes is one of the most prevalent diseases in the current century and is expected to increase more quickly in developing countries (18). Apart from the changed lifestyle and diet, it has been proved that exposure to some environmental pollutants can increase the risk of diabetes in susceptible people. Heavy metals and pesticides have been identified as the major diabetogenic toxicants for which the probable relationship between environmental release and the risk of diabetes has been well documented by determining biochemical and molecular mechanisms (19-21). Therefore, presenting new therapeutic strategies from natural sources based on the recently known etiologies of the disease can be a promising approach to both the prevention and treatment of diabetes.

Diabetes has many etiologies, including the damage and destruction of pancreatic $\beta$-cells. There has been sufficient evidence on the occurrence of oxidative stress parameters in the biological samples of patients with diabetes (22). Oxidative stress caused by excessive free radicals and hyperglycemia is believed to damage cellular macromolecules in the islets of Langerhans and disrupt insulin gene expression and insulin release. Thus, antioxidants can improve the viability and function of islets by counteracting overproduced oxidants and maintaining cellular homeostasis (23). In fact, sustained hyperglycemia due to uncontrolled diabetes can gradually lead to glucose toxicity

Volume 28, July \& August 2020 manifested by oxidative stress and inflammatory responses. It has been reported that under such conditions, some intracellular compensatory cascades are activated, including the JNK pathway that has been shown to be involved in the dysfunction of pancreatic $\beta$ cell and induction of insulin resistance in peripheral tissues, both of which can deteriorate hyperglycemia and lead to following events $(24,25)$.

Plants are one of the main natural sources of antioxidants and are rich ineffective ingredients with a high capacity for scavenging free radicals and ROS. Evidence has suggested that antioxidant compounds from natural sources such as plants can positively affect a wide range of biological functions in the cells by virtue of their radical scavenging properties (13). Polyphenols are considered as the secondary metabolites of plants and act as potent antioxidants that can provide defense against overproduced oxidants and oxidative stress. Polyphenol-rich diets have been reported to protect against the development of many pathological conditions with chronic progress, such as diabetes (26).

C. spinosaL. is a known polyphenol-rich plant that exhibits good antioxidant activities (27). Glucoselowering effects have also been reported for this plant in experimental and clinical studies. The hypoglycemic and hypolipidemic effects of the $C$. spinosa extract in laboratory animal models of diabetes caused by insulin deficiency and insulin resistance have been documented 
in different studies (28-33). The inhibitory effect of the C. spinosa extract on the activity of pancreatic alphaamylase has also been confirmed. Drugs inhibiting the enzymatic activity of $\alpha$-amylase and $\alpha$-glucosidase are helpful in the treatment of diabetes by lowering postprandial glucose (34). This evidence suggests the protective role of ingredients in the $C$. spinosa extract on the metabolic profile of carbohydrates and lipids. Moreover, histological studies have demonstrated that the $C$. spinosa extract can decrease cell necrosis and tissue damage in diabetic laboratory animals. This effect can be mediated by the active ingredients of the plants, most commonly phenols and flavonols that have antioxidant and anti-inflammatory activities (35).

The present study is the first report on the protective effects of $C$. spinosa on the pancreatic islets whose integrity and function are essential for the maintenance of glucose metabolism since the pancreas is the only source of insulin production in the body. The $C$. spinose extract increased the viability of rat pancreatic islets of Langerhans in a dose-dependent manner. Moreover, the amount of ROS, which is the main indicator of oxidative stress, was decreased in the islets treated with the $C$. spinose extract. Oxidative stress plays a major role in depleting cellular ATP and initiating cell death procedures, especially in pancreatic $\beta$-cells that are highly sensitive to oxidants and reactive metabolites. In this way, the agents having antioxidant capacity have been proposed to be useful against $\beta$-cell damage and insulin synthesis and secretion disruption. Previous research has also reported anti-inflammatory activities for the $C$. spinose extract in different animal models of experimental setups (36). Of course, these effects are predictable since oxidative stress and inflammation develop together in the cells and most of their elements interact with and augment one another. Given that the pathogenesis of diabetes involves the activation of both oxidative and inflammatory pathways, agents having antioxidant and anti-inflammatory effects can be helpful in the treatment of the disease. According to previous evidence on the glucose-lowering activity of $C$. spinosa, as well as its protective effects on the isolated islets of Langerhans observed in this study, it is concluded that the active ingredients of this plant can be regarded as a promising adjuvant therapy for the prophylaxis and management of diabetes, and merit further research to uncover the exact mechanisms responsible for this action.

\section{Conclusion}

The present findings showed that the $C$. spinose bud extract from the Moghan region is a source of polyphenol and can enhance the viability and reduce the production of ROS in the islets of Langerhans. Accordingly, C. spinosa can be evaluated for use in the prophylaxis and treatment of diabetes.

\section{Acknowledgments}

The authors wish to thank the Department of Toxicology and Diseases, The Institute of Pharmaceutical Sciences (TIPS) at Tehran University of Medical Sciences, Tehran, Iran for technical support.

\section{Conflict of Interest}

Authors declared no conflict of interest.

\section{References}

1. Zhang HN, He JH, Yuan L, Lin ZB. In vitro and in vivo protective effect of Ganodermalucidum polysaccharides on alloxan-induced pancreatic islets damage. Life Sci. 2003;73(18): 2307-19. [DOI:10.1016/S0024-3205(03)00594-0]

2. Sasso FC, De Nicola L, Carbonara O, et al. Cardiovascular risk factors and disease management in type 2 diabetic patients with diabetic nephropathy. Diabetes Care. 2006;29(3): 498-503. [DOI:10.2337/diacare.29.03.06.dc051776]

3. Cho NH , Shaw JE, Karuranga S, et al. IDF Diabetes Atlas: Global estimates of diabetes prevalence for 2017 and projections for 2045. Diabetes Res ClinPrac. 2018; 138: 271-281. [DOI:10.1016/j.diabres.2018.02.023]

4. Abdollahi M, Moridani MY, Aruoma OI, Mostafalou S. Oxidative stress in aging. Oxid Med Cell Longev. 2014;2014. [DOI:10.1155/2014/876834]

5. Prakash D, Suri S, Upadhyay G, Singh BN. Total phenol, antioxidant and free radical scavenging activities of some medicinal plants. Int $\mathrm{J}$ Food SciNutr. $\quad 2007 ; 58(1)$ : $\quad 18-28$. [DOI:10.1080/09637480601093269]

6. Rahimifard M, Navaii-Nigjeh M, NilliAhmadabadi A, et al. On the benefit of pure glycyrrhizic acid on the function and metabolic activity of isolated pancreatic Langerhans islets in vitro. Asian J Anim Vet Adv; 2012;7(11): 12128. [DOI:10.3923/ajava.2012.1212.1218]

7. Chen C, Pearson A, Gray J. Effects of synthetic antioxidants (BHA, BHT and PG) on the mutagenicity of IQ-like compounds. Food Chem. 1992;43(3): 177-83. [DOI:10.1016/03088146(92)90170-7] 
8. Grover J, Yadav S, Vats V. Medicinal plants of India with anti-diabetic potential. J Ethnopharmacol. 2002;81(1): $\quad 81-100$. [DOI:10.1016/S0378-8741(02)00059-4]

9. Mousavi SH, Hosseini A, Bakhtiari E, Rakhshandeh H. Capparisspinosa reduces doxorubicin-induced cardio-toxicity in cardiomyoblast cells. Avicenna J Phytomed. 2016;6(5): 488.

10. Rahnavard R, Razavi N. A review on the medical effects of Capparisspinosa L. Adv Herb Med. 2016;2(1): 44-53.

11. Meot-Duros L, Magne C. Antioxidant activity and phenol content of Crithmummaritimum L. leaves. Plant PhysiolBiochem. 2009;47(1): 37-41. [DOI:10.1016/j.plaphy.2008.09.006]

12. Yu L, Haley S, Perret J, Harris M, Wilson J, Qian $M$. Free radical scavenging properties of wheat extracts. J Agric Food Chem. 2002;50(6): 161924. [DOI:10.1021/jf010964p]

13. Zhao L, Liu W, Xiong S, et al. Determination of total flavonoids contents and antioxidant activity of Ginkgo biloba leaf by near-infrared reflectance method. Int J Anal Chem. 2018; 2018: 8195784. [DOI:10.1155/2018/8195784]

14. Kumaran A, Karunakaran RJ. In vitro antioxidant activities of methanol extracts of five Phyllanthus species from India. LWT-Food SciTechnol. 2007;40(2):

344-52. [DOI:10.1016/j.1wt.2005.09.011]

15. Mohammadi P, Rahimifard M, Baeeri M, Abdollahi M, Mostafalou S. Mechanistic assessment of cadmium toxicity in association with the functions of estrogen receptors in the Langerhans islets. Iran $\mathbf{J}$ Basic Med Sci. 2019;22(4): 445-51.

16. Mostafalou S, Baeeri M, Bahadar H, Gholami M, Abdollahi M. Molecular mechanisms involved in lead induced disruption of hepatic and pancreatic glucose metabolism. Environ ToxicolPharmacol. 2015;39(1)

16-26.

[DOI:10.1016/j.etap.2014.11.001]

17. Nili-Ahmadabadi A, Pourkhalili N, Fouladdel S, et al. On the biochemical and molecular mechanisms by which malathion induces dysfunction in pancreatic islets in vivo and in vitro. Pest Biochem Physiol. 2013;106(1-2): 5160. [DOI:10.1016/j.pestbp.2013.04.003]

18. Bahadar H, Mostafalou S, Abdollahi M. Growing burden of diabetes in Pakistan and the possible role of arsenic and pesticides. J Diabetes MetabDisord. 2014;13(1):

117 [DOI:10.1186/s40200-014-0117-y]
19. Mostafalou S, Abdollahi M. Pesticides and human chronic diseases; evidences, mechanisms, and perspectives. 2013;268(2): ToxicolApplPharmacol. [DOI:10.1016/j.taap.2013.01.025]

20. Mostafalou S, Abdollahi M. Pesticides: an update of human exposure and toxicity. Arch Toxicol. 2017;91(2): 549-599. [DOI:10.1007/s00204-0161849-x]

21. Mostafalou S, Abdollahi M. The role of environmental pollution of pesticides in human diabetes. Int J Pharmacol. 2012;8(2): 139-140 [DOI:10.3923/ijp.2012.139.140]

22. Astaneie F, Afshari M, Mojtahedi A. Total antioxidant capacity and levels of epidermal growth factor and nitric oxide in blood and saliva of insulin-dependent diabetic patients. Arch Med Res. 2005;36(4): 376-381. [DOI:10.1016/j.arcmed.2005.03.007]

23. Kaneto H, Katakami N, Kawamori D, et al. Involvement of oxidative stress in the pathogenesis of diabetes. Antioxid Redox Signal. 2007;9(3): 355-66. [DOI:10.1089/ars.2006.1465]

24. Kaneto H, Xu G, Fujii N, Kim S, Bonner-Weir S, Weir GC. Involvement of c-Jun N-terminal kinase in oxidative stress-mediated suppression of insulin gene expression. J Biol Chem. 2002;277(33): $\quad 30010-8$ [DOI:10.1074/jbc.M202066200]

25. Mostafalou S, Eghbal MA, Nili-Ahmadabadi A, Baeeri M, Abdollahi M. Biochemical evidence on the potential role of organophosphates in hepatic glucose metabolism toward insulin resistance through inflammatory signaling and free radical pathways. ToxicolInd Health. 2012;28(9): 840851 [DOI:10.1177/0748233711425073]

26. Pandey KB, Rizvi SI. Plant polyphenols as dietary antioxidants in human health and disease. Oxid Med Cell Longev. 2009;2(5): 270-8. [DOI:10.4161/oxim.2.5.9498]

27. Germano MP, De Pasquale R, D'angelo V, Catania S, Silvari V, Costa C. Evaluation of extracts and isolated fraction from Capparisspinosa L. buds as an antioxidant source. J Agric Food Chem. 2002;50(5): 1168-71. [DOI:10.1021/jf010678d]

28. Mishra P, Panda P, Chowdary K, Panigrahi S. Antidiabetic and antihyperlipidemic activity of Capparisspinosa extract. Int J Pharm Sci Rev Res. 2012;14(1): 38-43.

29. Eddouks M, Lemhadri A, Michel JB. Hypolipidemic activity of aqueous extract of Capparisspinosa L. in normal and diabetic rats. J Ethnopharmacol. 2005;98: 345-350. [DOI:10.1016/j.jep.2005.01.053] 
30. Kazemian M, Haeri MR, Ebrahimi M, Heidari R. Anti-diabetic effect of Capparisspinosa L. root extract in diabetic rats. Avicenna $\mathrm{J}$ Phytomed. 2015;5(4): 325-32.

31. Lemhadri A, Eddouks M, Sulpice T, Burcelin R. Anti-hyperglycaemic and anti-obesity effects of Capparisspinosa and Chamaemelumnobile Aqueous extracts in HFD Mice. American J PharmacolToxicol. 2007;2(3): 106-110. [DOI:10.3844/ajptsp.2007.106.110]

32. Rahmani R, Mahmoodi M, Karimi M, Hosseini F, Heydari R, Salehi M, Yousefi A. Effect of hydroalcoholic extract of CapparisSpinosa fruit on blood sugar and lipid profile of diabetic and normal rats. Zahedan J Res Med Sci. 2013;15(11): 34-38.

33. Oudah SK, Al-Salih RMH, Gusar SH. Study the role of polyphenolic extract of CapparisSpinosa
L. leaves as a hypoglycemic agent. Int J SciEng Res. 2014;5(5): 1561-75.

34. Selfayan M, Namjooyan F. Inhibitory effect of Capparisspinosa extract on pancreatic alphaamylase activity. Zahedan J Res Med Sci. 2016;18(4): e6450 [DOI:10.17795/zjrms-6450]

35. Taghavi M, Nazari M, Rahmani R, et al. Outcome of Capparisspinosa fruit extracts treatment on liver, kidney, pancreas and stomach tissues in normal and diabetic rats. Med chem. 2014;4: 717 21. [DOI:10.4172/2161-0444.1000218]

36. Zhou H, Jian R, Kang J, et al. Anti-inflammatory effects of caper (C. spinosa L.) fruit aqueous extract and the isolation of main phytochemicals. J Agric Food Chem. 2010; 58(24): 12717-21. [DOI:10.1021/jf1034114]

\section{How to Cite This Article:}

Azad M, Mohammadi P, Bohlooli S, Mostafalou S. Protective Effect of Capparis spinosa Hydroalcoholic Extract on the Integrity of Rat Pancreatic Islets. J Adv Med Biomed Res. 2020; 28 (129):204-211

\section{Download citation:}

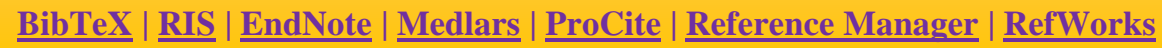

\section{Send citation to:}

90. Mendeley Zotero OPefwork $\underline{\text { RefWorks }}$ 